\title{
The Political Economy of Boomerang Aid in China's Tibet
}

Lecturer in Population and Social Policy, Institute of Social Studies, The Hague

\section{Andrew Martin Fischer}

\section{(2) OpenEdition}

\section{Journals}

Édition électronique

URL : http://journals.openedition.org/chinaperspectives/4842

DOI : $10.4000 /$ chinaperspectives.4842

ISSN : 1996-4617

Éditeur

Centre d'étude français sur la Chine contemporaine

Édition imprimée

Date de publication : 1 septembre 2009

ISSN : 2070-3449

Référence électronique

Andrew Martin Fischer, "The Political Economy of Boomerang Aid in China's Tibet », China

Perspectives [En ligne], 2009/3 | 2009, mis en ligne le 01 septembre 2012, consulté le 28 octobre 2019. URL : http://journals.openedition.org/chinaperspectives/4842 ; DOI : 10.4000/chinaperspectives.4842

(c) All rights reserved 
(1)

$\geq$ The Political Economy of Boomerang Aid in China's Tibet ANDREW MARTIN FISCHER

This article examines how rapid growth in the Tibetan areas of West China since the mid-1990s has been a key factor exacerbating the unresolved contestations of Chinese rule in these areas. Amidst the continued political disempowerment of Tibetan locals, Beijing has used recent development strategies to channel massive amounts of subsidies through the government itself or through Chinese corporations based outside the Tibetan areas, thereby accentuating the already highly-externalised orientation of the local economy. These processes offer important insight into the recent explosion of tensions.

W hile large-scale demonstrations were still fanning out from Lhasa to the rest of the Tibetan areas in March 2008, the usual developmental alibi were being laid out by the Chinese Communist Party (CCP). Beijing argued that the "riots" (in reference to the riot in Lhasa on 14 March) were due to political meddling and manipulation from abroad, particularly from the Tibetan exile community and their Western supporters; given that the region had been experiencing ample development and rising prosperity, local Tibetans had no valid cause for grievance. This line was supported by the regular collection of Western scholars and commentators who, at the extreme, tended to interpret the events as the covert handiwork of U.S. neocons. ${ }^{(1)}$

Indeed, absolute economic and human development indicators offer little insight into the reasons why Tibetans might have been so aggrieved. Poverty rates had been falling, average household incomes rising, and levels of educational attainment moderately improving. Were it not for some restrictions on cultural or religious practice, or the worrisome rise in inequalities, many argued that the government had been tending well the disadvantaged position of Tibetans in China. Many Chinese commentators went so far as to conclude that Tibetans, lavishly coddled by central government subsidies to a far greater extent than any other minority nationality in China, are quite simply spoilt, complaining with their stomachs full. ${ }^{(2)}$

This simplistic developmental discourse unfortunately ignores how the manner by which western development strategies have been implemented in the Tibetan areas since the mid-1990s has itself been a key factor exacerbating the unresolved contestations of Chinese rule in these areas. Within a context of continued political disempowerment of Tibetan locals, these strategies have channelled massive amounts of subsidies and subsidised investments (relative to the local economy) through the government itself or else through Chinese corporations based outside the Tibetan areas. This has accentuated the already highly externalised orientation of wealth flows in the economy, resulting in a socio-economic structure that rewards a small upper stratum, which includes a small minority of Tibetans and a large proportion of nonTibetan migrants, mostly concentrated in urban areas and well positioned to access the flows of wealth as they pass through the region with increasing velocity.

Subsidisation strategies thus result in a form of "boomerang aid." Subsidies largely return to their sender while debilitating indigenously-oriented forms of wealth creation and accumulation in most sectors of the economy outside agriculture. This reinforces a situation of extraordinary inefficiency and extreme dependence, as well as strong cultural, linguistic, and political biases that derive from axes of advantage stemming from characteristics of the dominant cultural and political group, such as Chinese fluency, Chinese work cultures, and connections to government or business networks in

1. The most prominent Western scholar in this regard is Barry Sautman, "Protests in Tibet and separatism: The Olympics and beyond," China Left Review, 2008, 1. For an extreme position, see W. Engdahl, "Risky geopolitical game: Washington plays 'Tibet roulette' with China," Center for Research on Globalization, 10 April 2008. See Emily T. Yeh, "Tibet and the problem of radical reductionism," Antipode, forthcoming (August or October 2009), for an excellent review and critique of this literature.

2. Again, see Sautman, art. cit., for allusions to these arguments. 
China Proper. These biases are most evident in the context of competition with non-Tibetan migrants from other parts of China, which I have discussed elsewhere. ${ }^{(3)}$ Nonetheless, it is important to note that the in-migration of non-Tibetan (and Tibetan) outsiders is itself driven by the polarising implications of these development strategies.

This is an important distinction from the argument that ethnic inequalities in the TAR and other Tibetan areas are the result of spatial inequalities (i.e. that Tibetans are mostly rural and poor, hence ethnic inequalities reflect urban-rural inequality). ${ }^{(4)}$ Rather, inequalities differ from elsewhere in China in that they are instituted through the special treatment accorded to the Tibetan areas by the Chinese state, which results in a progressive appropriation of ownership in the local economy by outsiders, placing local Tibetans at a disadvantage despite the profusion of subsidies. The degree to which discrimination is specifically or systematically intended within these strategies is perhaps less important than the fact that the result is effectively discriminatory. In any case, the strong perception of discrimination in the eyes of local Tibetans offers important insights into the explosion of tensions in March 2008.

The article is based on an ongoing project of quantitative analysis of official statistical data combined with over a year of cumulated fieldwork in Western China from 2003 to 2008. ${ }^{(5)}$ The analysis focuses on the Tibet Autonomous Region (TAR) by necessity, given that the TAR is the only province-level jurisdiction that is indigenously Tibetan in its entirety, whereas Han Chinese dominate both the rural and urban data of Qinghai, the province with the next highest proportion of Tibetans in its population. The focus is nonetheless appropriate for this study given that the TAR is the reference point of arguments that Beijing lavishes resources on Tibetans. If the argument is tenuous in the TAR, it is likely to be irrelevant in the Tibetan areas outside the TAR, which are much less fiscally privileged than the TAR even though exhibiting many of the same structural disadvantages, such as extreme lags in education levels.

The article is divided into three sections. The first reviews the economic lagging of the TAR in the early part of the reform period and its subsequent economic take-off from the mid1990s onwards. The second examines the heavily subsidised sources of this take-off through an analysis of government expenditure and investment. The last section explores how instituted patterns of ownership accentuate the externally-dependent and ethnically-discriminatory characteristics of growth. The article concludes with reflections on the conflictive implications of Chinese boomerang aid to Tibetan areas.

\section{The economic bust and boom of Tibet in the reform period}

The speed of recent economic growth in the TAR has been phenomenal, even by recent Chinese standards. The Gross Domestic Product (GDP) of the TAR more than quadrupled from 1997 to 2007. In comparison, the Chinese economy tripled over the same period, which was the fastest (and largest) experience of rapid economic growth the world had ever seen. In the TAR, growth had been about one-third faster.

This had not always been the case. The TAR and Qinghai, which together account for about three-quarters of the $\mathrm{Ti}$ betan population and territory in China, had been the worst cases of economic lagging in China from the beginning of the reform period until the mid-1990s. Lagging was not merely relative to the take-off in Eastern China; the TAR was actually in recession in real per capita terms (i.e., accounting for price inflation and population growth) for much of the 1980s and up until the mid-1990s. As a result, the per capita GDP of the TAR fell to the second lowest in China in 1996. Economic conditions in the Tibetan areas outside the TAR were probably similar if not worse, given that they were much less fiscally privileged than the TAR, and thus more severely affected by these dynamics of regional development.

Economic lagging derived from several major shifts in regional development policy that accompanied the reform period, resulting in immediate macroeconomic stagnation in northwest China and the TAR in the early 1980s. Industrial investment was redirected away from the interior and towards the coastal areas. Fiscal decentralisation and enterprise reforms quickly eroded the system of regional redistribution, resulting in a marked decline in the level of subsidy that was directed by the centre to the western provinces. ${ }^{(6)}$

3. See Andrew Fischer, State Growth and Social Exclusion in Tibet: Challenges of Recent Economic Growth, Copenhagen, Nordic Institute of Asian Studies Press, 2005; Andrew Fischer, "A Theory of Polarisation, Exclusion and Conflict within Disempowered Development: The case of contemporary Tibet in China," PhD thesis, London School of Economics, 2007; Andrew Fischer, "'Population Invasion' versus Urban Exclusion in the Tibetan Areas of Western China," Population and Development Review, vol. 34, $\mathrm{n}^{\circ} 4$ 2008, pp. 631-662; Andrew Fischer, "Educating for Exclusion in Western China: Structural and Institutional Dimensions of Conflict in the Tibetan Areas of Qinghai and Tibet," CRISE Working Paper (July 2009), Oxford, Centre for Research on Inequality, Security and Ethnicity, Queen Elizabeth House; http://www.crise.ox.ac.uk/ abstract.shtml?wp69.

4. See Barry Sautman and Irene Eng, "Tibet: Development for Whom?," China Information, vol. XV, $n^{\circ} 2,2001$, pp. 20-74

5. See the appendix in Andrew Fischer, "'Population Invasion' versus Urban Exclusion in the Tibetan Areas of Western China," art. cit., for details on the data and methods used.

6. For an excellent discussion of local government finance in China, see Christine Wong (ed.), Financing Local Government in the PRC, Hong Kong, New York, Oxford University Press, 1997. 
Figure 1. Sectoral shares of total GDP of the TAR (current value)

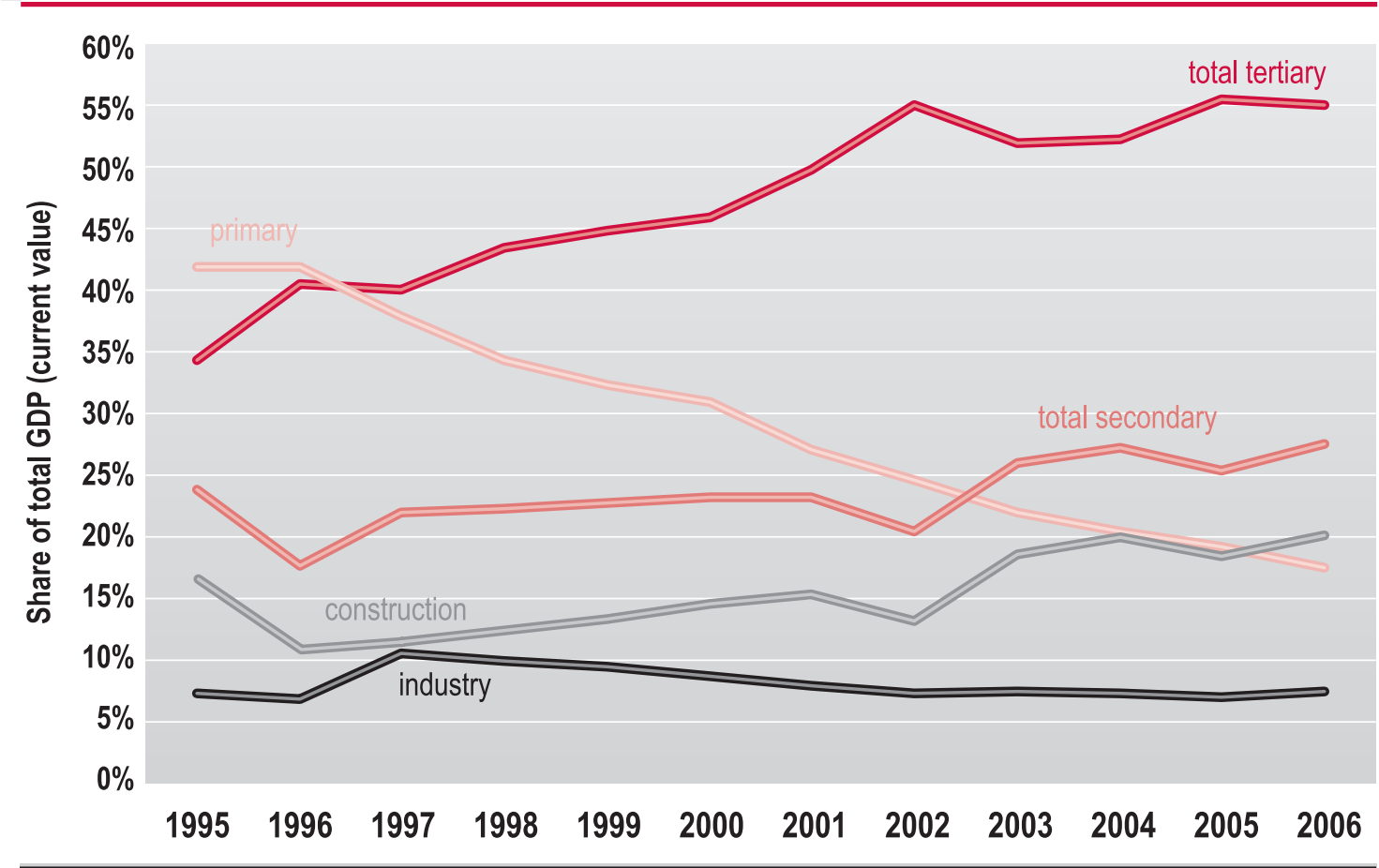

Sources: calculated from China Statistical Yearbook (2007, Tables 3-12 and 3-13) and equivalent tables in earlier China Statistical Yearbooks; Tibet Statistical Yearbook (2003, Table 1-12).

However, the strategy of under-pricing agricultural and raw material output was maintained up until the early 1990s as a means of subsidising coastal industries. The combination had a disproportionately depressing impact on the western provinces, given that their economies were more agrarian or raw material-based than the coastal areas, and that their public revenues were heavily dependent on subsidies. The Tibetan areas were especially impacted given that they were the most agrarian in China. ${ }^{(7)}$

Such realities were not overlooked, and several decisive policy initiatives were taken. ${ }^{(8)}$ These included: the 8-7 poverty reduction plan in 1994, complemented in the TAR by the Third Tibet Work Forum; the focus on western development in the Ninth Five-Year Plan (1996-2000); and the "Open the West" campaign (OWC; xibu da kaifa) announced in 1999, which complemented the Tenth Five-Year Plan and was supported in the TAR by the Fourth Tibet Work Forum in 2001. As a result, spending and investment increased in the western region, and economic growth picked up from the mid-1990s onwards. Rapid growth started in the TAR in 1996, surpassing national growth rates from 1996 to 1999 and again from 2001 to 2003. Rapid growth started in Qinghai in 1998.
However, this rapid growth in the TAR was dislocated from productive sectors, particularly agriculture, which was the largest sector up to 1996 and employed about three quarters of the workforce in 2000 (mostly Tibetan). While aggregate GDP in the TAR doubled from 2000 to 2005, the GDP contribution of agriculture only grew by about one third, falling in share from 42 percent of GDP in 1995 to 17.5 percent in 2006. Industry and mining grew from a very small base by about three quarters, remaining at around 7 percent of GDP. On the other hand, the GDP value of construction almost tripled, increasing from around 11 percent of GDP in 1996 to 20 percent in 2006, becoming larger than agriculture and almost three times larger than industry and mining (in every other province in China, construction is only a fraction of industry). Although construction was disconnected from productive activities, it was closely related to the tertiary sector (a combination of government and party adminis-

7. See Dali Yang, Beyond Beijing: Liberalization and the Regions in China, London, Routledge, 1997, and Fischer, State Growth and Social Exclusion in Tibet, op. cit., for more detail on these dynamics of regional development.

8. See Yang, Beyond Beijing, op. cit., on debates in China about these issues in the early to mid-1990s. 
Figure 2. Share of selected categories in the tertiary sector, TAR

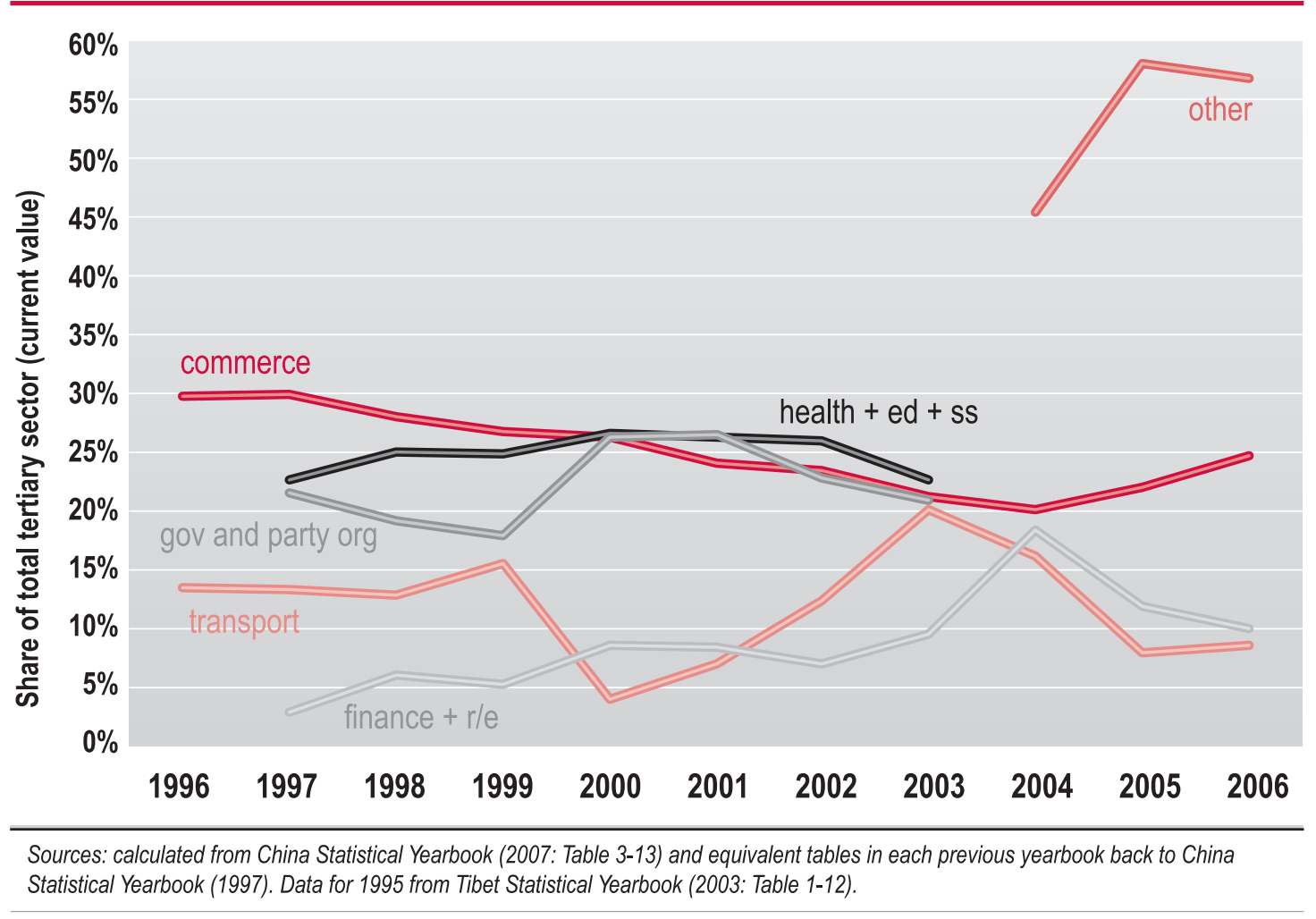

tration; social services such as education and health; trade and commerce; transport; and various other services), which also almost tripled. The tertiary sector rose from 34 percent of total GDP in 1995 to 55 percent by 2006, becoming the largest sector of the TAR (see Figure 1).

The experience of the TAR was starkly dissimilar to all other provinces of western China, including Qinghai, the province most similar to the TAR in terms of topography and demography. Subsidisation strategies in all other western provinces were focused on intensively restructuring the antiquated industrial base left over from Maoist interior industrialisation strategies of the 1960s and 1970s. In all these cases, intensive subsidisation and construction activity bolstered the leading role of the industry within a few years. In China as a whole, secondary industry (including mining, but only as a very minor share) was generally the largest sector driving growth throughout the 1990s and 2000s, amounting to over 40 percent of GDP. Construction actually shrank from 6.1 to 5.6 percent of GDP over this period despite the evident construction boom in China. The share of the tertiary sector increased considerably, but settled at just under 40 percent by 2006. ${ }^{(9)}$ These patterns were broadly similar in most western provinces, albeit with a stronger role of the tertiary sector and construction since 2000, reflecting the larger role of subsidies and investment under the OWC. ${ }^{(10)}$ In contrast, rapid growth in the TAR has been based on rapid tertiarisation and a construction boom alongside de-industrialisation (i.e., a shrinking GDP share of secondary industry). The government argues that the new strategy for the TAR is to move away from past strenuous efforts to create a secondary industrial base in the TAR and to concentrate instead on tertiary industries (such as tourism) as the new lead pillars of growth. Indeed, the overwhelming role of the tertiary sector does beg for further analysis.

In this regard, the TAR again contrasts with the rest of China. While the tertiary share of government and party agencies in the TAR has always been the highest in China, at around 20 percent in the mid-1990s, it surged in 2000 and 2001 to over 26 percent, becoming the largest compo-

9. All data calculated from National Bureau of Statistics, China Statistical Yearbook, Beijing, China Statistical Press, 2007, Table 3-1. In subsequent footnotes, CSY will refer to China Statistical Yearbook.

10. See Fischer, "A Theory of Polarisation," op. cit., for more detail on Sichuan, Gansu, Qinghai, and all China. 
Figure 3. Sectoral contributing rates to GDP increase, TAR

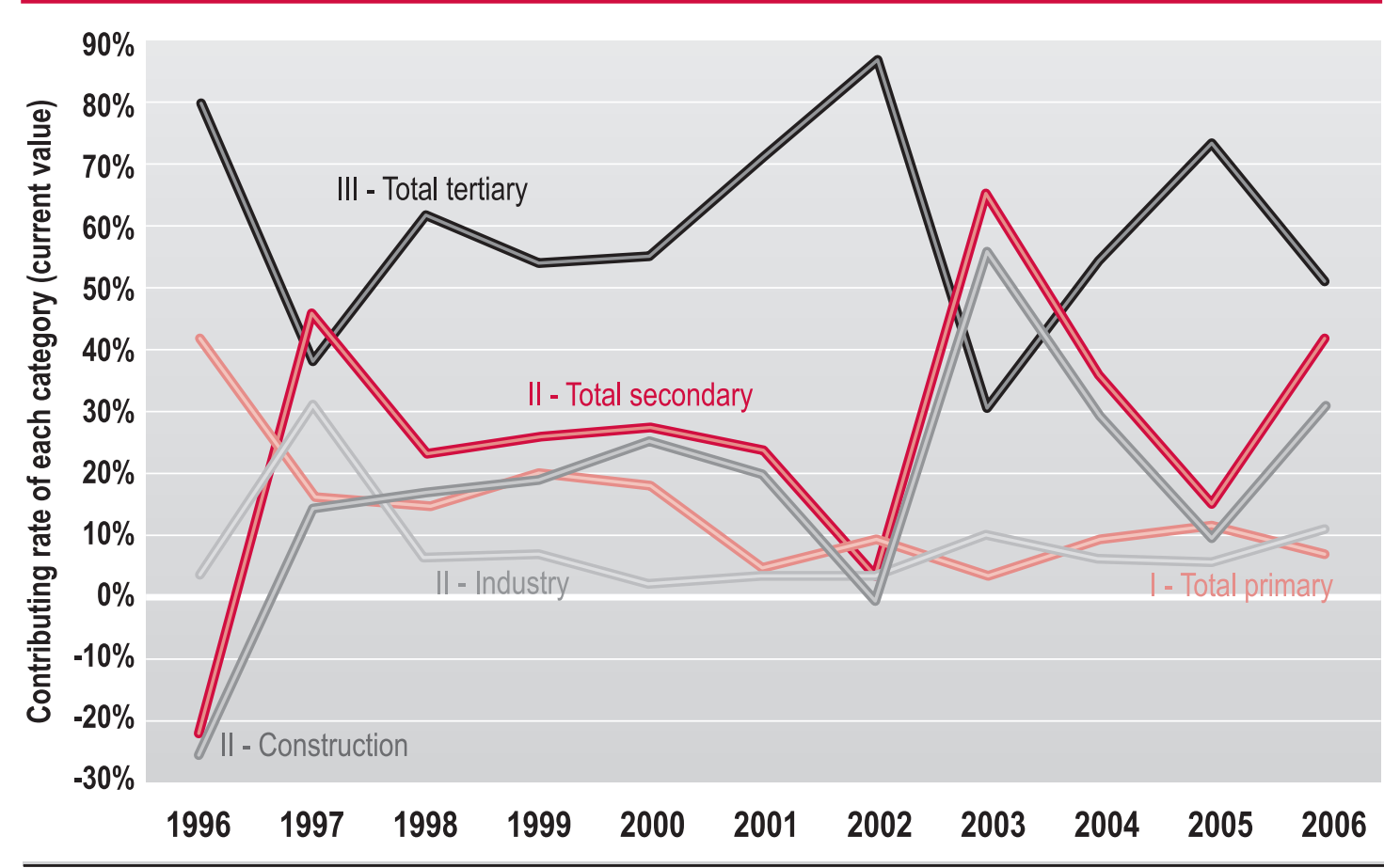

Sources: see Figure 2.

nent of the tertiary sector in those two years and accounting for over 13 percent of total GDP in 2001, or almost twice the entire mining and industrial activity and close to the total construction activity as well. Government administration had effectively become the "engine of growth" in the opening years of the OWC, growing 68 percent in 2000 and 28 percent in 2001. Its share fell slightly in the following years and was surpassed by social services (health $+\mathrm{ed}+\mathrm{ss}$ ), although the category of "other" (see Figure 2) seems to suggest that government administration continued to play a leading role in growth up to 2006. The category of "other" represents an aggregation of all those tertiary categories no longer reported from 2004 onwards, of which government administration and social services are the largest components. Government administration probably maintained its share within this category, given fairly proportionate increases in government expenditure in both government administration and social services. Given the rising GDP share of the tertiary sector up to 2006, it is therefore likely that government administration maintained a share of overall GDP at around 13 percent if not more. In comparison, government administration in China accounted for only 2.7 percent of total GDP in 2006, while it accounted for 7.7 percent in Qinghai.
The unusually large and rapidly growing category of government administration in the TAR (as well as in Qinghai and Xinjiang, where it also grew rapidly in 2000 and 2001) might indirectly indicate a military and/or security focus of the OWC in these provinces. This is of course a matter of speculation, as military activity is a closely guarded secret in China. However, the inference is supported by observations of expansion in military facilities around Lhasa during these years.

These patterns are further clarified by the contribution of select sectors to growth in each year, calculated from the above data (see Figure 3). In China and most western provinces, the largest sectoral contribution generally came from industry and mining, in line with the above analysis. In the TAR, the tertiary sector played the leading role in contributing to GDP growth up to 2006, besides a brief interlude in 2003 when it was surpassed by a huge surge in the secondary sector, almost entirely due to construction that accounted for 56 percent of GDP growth in that year. The surge was likely related to the Qinghai-Tibet railway construction, which entered the TAR on a large scale in that year. Otherwise, tertiary activities were contributing on average well over 50 percent of total GDP increase throughout this period, reaching 
Figure 4. Selected tertiary contributing rates to total GPD increase, TAR

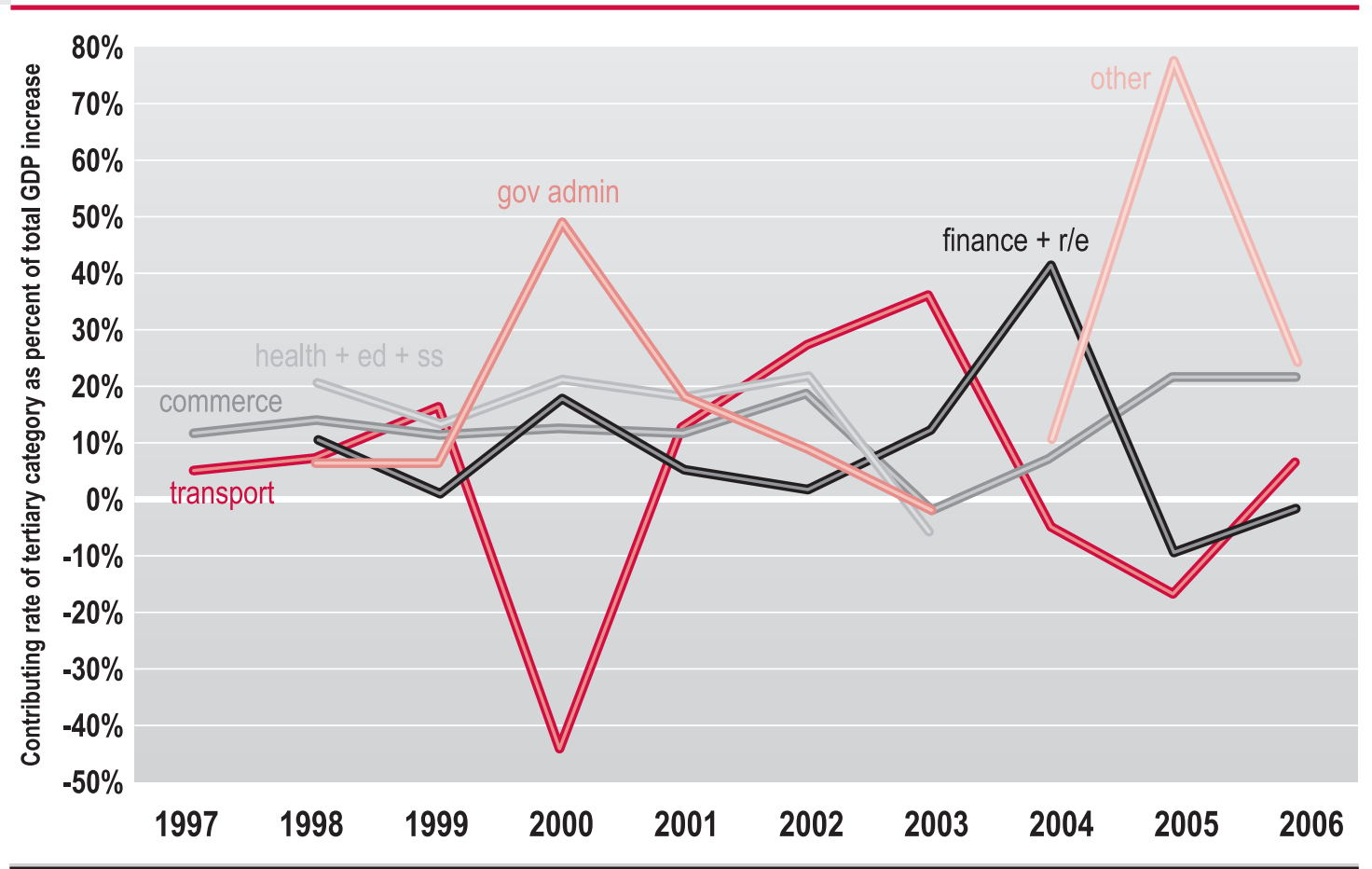

Sources: see Figure 2.

high points of 80 percent in 1996, 87 percent in 2002, and 73 percent in 2005. This means that the sector was not only large (in terms of GDP share), but also growing fast (share of GDP growth), in contrast to agriculture, which was large but contributing little to GDP growth. The other important feature to note is the degree to which construction almost entirely dominated the contribution of the secondary sector right up to 2006, while the contribution of industry was marginal at best, bearing little relation to the contributions of construction or the tertiary sector.

The tertiary contribution is shown in more detail in Figure 4. Government administration contributed 49 percent of total GDP increase in 2000, accounting for most of the total tertiary contribution of 55 percent in that year. This entirely subsidy-induced performance tapered off by 2003, as construction (shown previously) and transport took over as the main sources of growth. However, as the major phases of railway construction were wrapping up after 2004, the tertiary category of "other" took off, contributing 78 percent of total GDP growth in 2005. As previously noted, we can safely assume that about half of this increase in "other" came from the expansion of government administration. From this perspective, although tourism had been booming throughout this period and undoubtedly fuelled an urban commercial boom, ${ }^{\text {(II) }}$ tourism nonetheless played a secondary role in driving growth next to government administration (and related military and paramilitary activities not included in these statistics).

In other words, most of the growth generated in the TAR over these years derived from an alternating sequencing between tertiary activities (dominated by government administration) and construction (dominated by large construction projects such as the various components of the QinghaiTibet railway). Both of these drivers were mostly determined by policies of subsidised spending and investment decided in Beijing and, to a much lesser extent, supported by various rich coastal provinces in China. Given the weight of these instituted sources of growth in the local economy, changes in provincial economic structure have been much more radical and volatile than elsewhere in China, including the most similar province of Qinghai.

11. Tourist numbers to the TAR (mostly domestic Chinese) apparently reached 1.6 million in 2005 and over 4 million in 2007, exceeding the total population of the TAR of about 2.8 million in 2007 (see "Tertiary sector bolsters Tibet economy," People's Daily Online, 18 January 2006, http://english.peopledaily.com.cn/200601/19/eng20060119 236599.html; see also People's Daily "Official figures: Tibetan tourism booming before riots," People's Daily, 25 April 2008. 

In the case of investment, several unique characteristics sharply differentiate the composition of investment in the TAR from all other provinces in China, including Qinghai. ${ }^{(1)}$ First, investment in the TAR was dominated by stateowned units (SOUs), at 84 percent of total investment in 2004, in contrast to 52 percent in Qinghai, and only 36 percent in Sichuan and in China overall. Second, the largest sector of investment in the TAR was "transport, storage and post," at almost 36 percent of total investment in 2004. The railway would account for a large share of this. In contrast, the largest sector in all the other provinces was manufacturing, at almost 28 percent of total investment nationally in 2004. Manufacturing investment in the TAR was marginal at 4.3 percent of total investment, and only 0.6 percent of total investment was in mining. The second largest sector of investment in the TAR was in "public management and social organisation" (the investment term used for government administration), which accounted for 14 percent of total TAR investment in 2004, versus only 6 percent in education and 1 percent in "health, social security and social welfare." This was the inverse of every other province in China, where investment in education was usually double that in government administration. Finally, 59 percent of total investment in the TAR was financed by state budgetary appropriation in 2004, whereas this source of funding was relatively minor in other western provinces, at only 10 percent in Qinghai and 3 percent in Sichuan. In every province besides the TAR, the majority of investment funding comes from self-raised funds, i.e. reinvested profits. Self-raised funds were also the second most important source of funds in the TAR, at 22 percent of total investment, although given the predominance of out-of-province businesses, these funds were probably self-raised mostly outside of the TAR.

On this last point, although the provincial origins of investment are not divulged in the statistical sources, it is possible to offer some impressions in the case of the TAR. The 62 aid projects of the Ninth Five-Year Plan amounted to 4.6 billion yuan, shared equally between Beijing and various wealthy provinces. This was equivalent to more than half the GDP and 1.6 times total investment in the TAR in 1996. Similarly, under the rubric of the OWC and the Tenth FiveYear Plan, the central government announced that it would invest 31.2 billion yuan in the TAR, while various Chinese provinces would invest 1.06 billion yuan. ${ }^{(14)}$ Together, this was equivalent to about 2.7 times the GDP and 3.9 times the total investment in the TAR in 2001. The Qinghai-Tibet railway alone was projected at its outset in 2001 to require about 26 billion yuan in investment. ${ }^{(15)}$ This alone was al- most double the total GDP of the TAR in 2001. Even allowing for the fact that it was spread over several years and shared between both Qinghai and the TAR, the weight of this single project dwarfed the TAR economy during its construction phases. From this perspective, it is clear that most investment in the TAR derives from outside the province, whether from state budgetary appropriations or from the self-raised funds of state-owned enterprises based outside the province.

\section{Subsidies and investment as sources of growth}

The weight of subsidies in the TAR economy is shown in Figure 5 below, which measures the ratios of expenditures, subsidies, and investment to nominal GDP and compares these to real per capita GDP growth rates measured in constant 2006 prices. The measure for total subsidy (total subsidies/GDP) deducts government expenditure on capital construction in order to avoid double counting investment in the final measure of total direct and indirect subsidies. As noted above, this combined measure approximately reflects total subsidies only in the specific case of the TAR.

The TAR is exceptional in the degree to which it exhibited an extreme level of subsidy dependence that did not abate over time despite the intensity of investment activity. Local government expenditure remained over 90 percent funded by direct subsidies throughout this period ("budget sub/exp"). Moreover, direct budgetary subsidies reached an astonishing level of 81 percent of GDP in 2002. This fell to 64 percent in 2006, although even this level was very high in historical comparison. Notably, the huge bulge in the proportion of expenditure and subsidies to GDP from 2000 to 2004 and the shorter bulge after 2004 relate almost entirely to government expenditure on capital construction. The value of total investment reached levels unparalleled anywhere in China in recent history, at 77 percent of GDP in 2004 and almost 80 percent in 2006. The peak in 2004 was no doubt related to the ongoing construction of the railway in the TAR, which was completed in 2006. The renewed increase in 2006 seems to indicate that the government moved on to new construction projects.

The combined level of budgetary subsidy and subsidised investment to GDP presents the most striking picture of the

\footnotetext{
13. Investment data are calculated from China Statistical Yearbook, 2005, Tables 6-3, 6-4, 6-5, and 6-7.

14. TIN, China's Great Leap West, London, Tibet Information Network, 2000.

15. CSY, 2005, table 6-40.
} 
Figure 5. Expenditure, Subsidy and Investment, TAR, 1990-2006

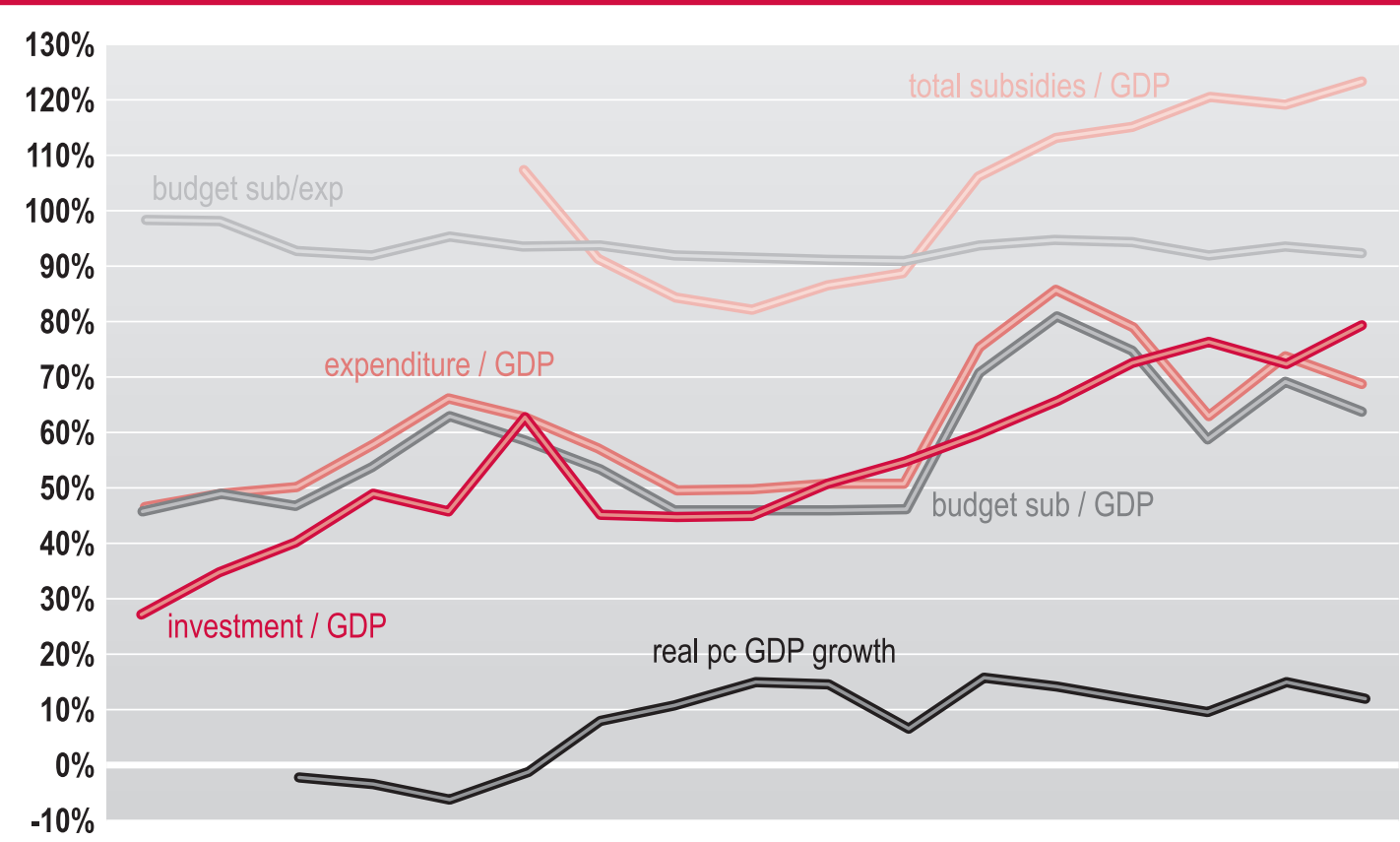

19901991199219931994199519961997199819992000200120022003200420052006

Sources: calculated from China Statistical Yearbook (2007: Tables 3-1. 3-12, 3-13, 6-3, 8-14, 8-15, and 9-5) and equivalent tables in previous yearbooks from 1996-2004; pre-1995 data from equivalent tables in Tibet Statistical Yearbooks.

total weight of subsidies in the TAR. Following an earlier peak of 107 percent of GDP in 1995, total subsidies surpassed 100 percent of GDP in 2001 and then climbed to 123 percent by 2006. In other words, the central and various provincial governments were apparently giving more money to the TAR than all of the (mostly subsidised) economic activity in the province combined.

With such intensive subsidisation, high growth rates are not at all surprising. Rather, it is the sheer inefficiency of such subsidisation that is striking. This can be characterised as a "negative multiplier effect" of subsidies and investment on growth. Normally, one dollar of investment or government spending produces several dollars worth of economic activity in a year, as the dollar spent is then spent again and again by others who earn these dollars. However, in the TAR there was only 0.5 yuan of GDP increase for every yuan of increased subsidies and investment in 2001. The situation had hardly improved by 2004, as there was only 0.65 yuan of GDP increase for each yuan of increased subsidies and investment. In Qinghai, the next most subsidised province in China, the multiplier fell below one for a few years in the late 1990s and early 2000s, reflecting the intense subsidisation of western development strategies over these years.
However, the multiplier returned positive (above one) after a few years, reflecting that such subsidisation was directed at industrial restructuring, as discussed previously.

The remarkable inefficiency of subsidisation in the TAR is not new, but has been consistent since the government started to intensively subsidise the region in the late 1960s. This was noted by Wang and Bai, ${ }^{(16)}$ who pointed out that for every one yuan increase in the value of output between 1957 and 1983 in the TAR, subsidies increased by 1.24 yuan, i.e. a negative multiplier effect. According to their data, the level of subsidy started to increase sharply in 1968. The proportion of central government subsidies to output value (equivalent to the subsidy/GDP measure above) increased from 31 percent in the 1950s to 45 percent in the 1960s, 80 percent in the 1970s, and 97 percent in 19801983. Or, the negative multiplier effect that they measured from 1957 to 1983 was mostly concentrated in the years from 1968 onwards. They did not clarify that this intensification of subsidies occurred simultaneously with the late implementation of collectivisation in the TAR in the midst of

16. Xiaoqiang Wang and Nanfeng Bai, The Poverty of Plenty, Basingstoke, Macmillan, 1991 (translated from the original Chinese version published in 1986). 
Figure 6. International Trade Balance of the TAR, 1993-2006

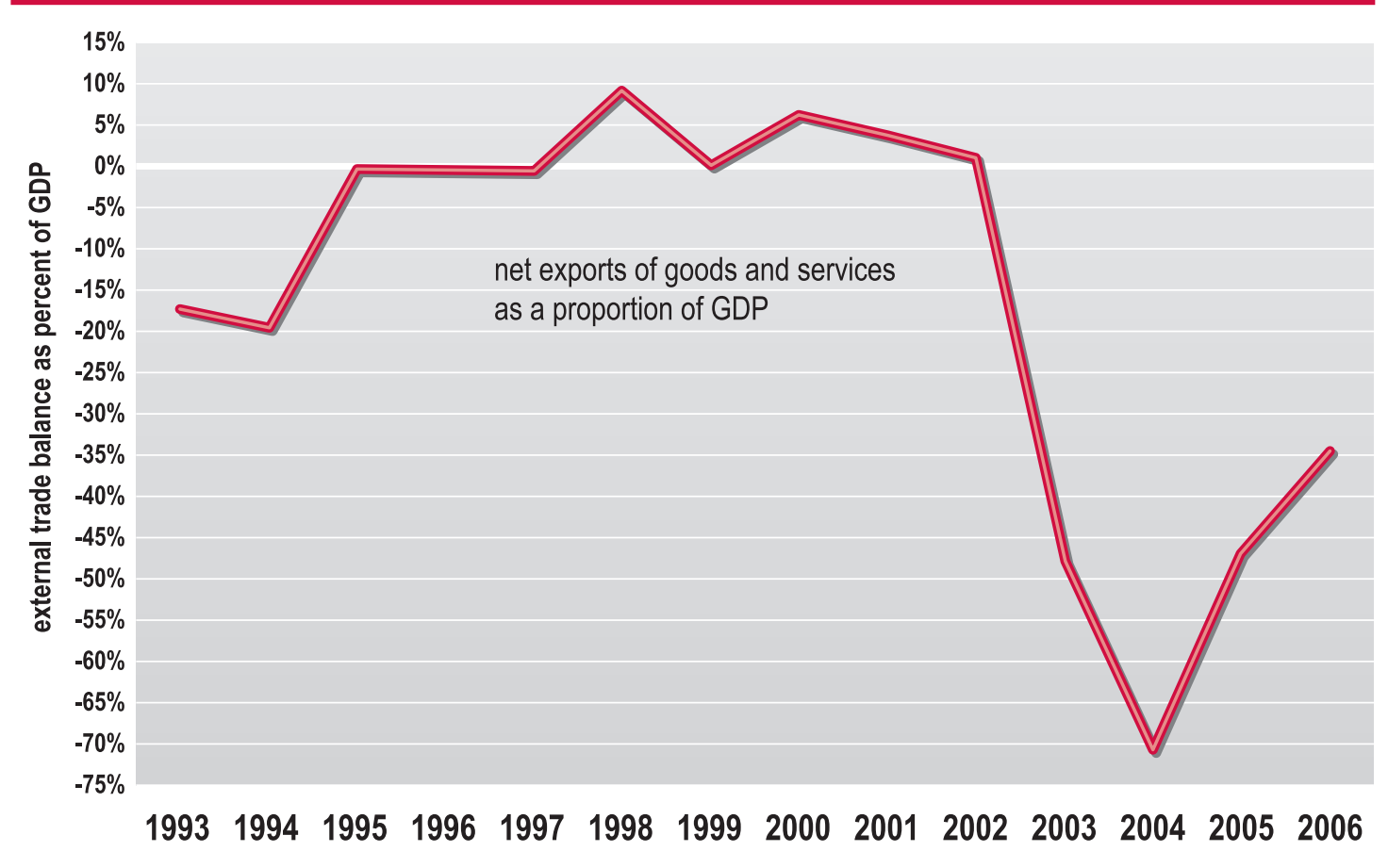

Source: calculated from China Statistical Yearbook (2007: Table 3-19) and equivalent tables in previous yearbooks.

the Cultural Revolution and intensive interior industrialisation strategies, discussed further in the next section.

Similar patterns continued even in the context of reform. For instance, the nominal value of government expenditure almost doubled in 1984 (to 75 percent of GDP), yet the economy only briefly came out of recession for about two years. Nominal government expenditure declined sharply in 1986 and then rose gradually thereafter, albeit more slowly than inflation, helping to explain the recessionary trend in real per capita GDP from the mid-1980s to the mid-1990s. It was only the combined immensity of subsidy and investment increases from the mid-1990s onwards that served to buoy up real per capita GDP, although in an extremely inefficient manner.

Returning to the present, the most logical reason that subsidies were greater than total GDP is that a large proportion of subsidies were spent on imports from abroad or from elsewhere in China. In principle, the resulting trade deficit is deducted from the provincial GDP data. For instance, the international trade balance of goods and services for the TAR suddenly fell from a slight surplus in 2002 to a massive deficit equivalent to 48 percent of GDP in 2003, 71 percent in 2004, and then back up to 34 percent in 2006 (see Fig- ure 6). This was similar to the trade deficit that mirrored the earlier bout of intensive investment from 1992 to 1994. The more recent deficit was likely due to the railway construction, which was heavily dependent on imports from abroad (such as rail carriages from Bombardier in Canada, IT services from Nortel, also in Canada, Japanese engineers, and so on). Deducting this bulge of imports from the calculation of subsidies would considerably reduce the level of subsidies as a proportion of GDP, at least from 2003 to 2006.

However, this does not explain the fact that total subsidies started to exceed GDP from 2001 onwards, even despite a trade surplus in 2001 and 2002. In other words, the overwhelming weight of subsidies in the TAR economy is more endemic than simply a one-time spending spree by the government on the latest high-tech railway gadgetry. Another explanation is that the subsidies were being similarly and instantly drained out of the local economy via a trade deficit with the rest of China. This point was one of the main critiques made by Wang and Bai, who noted that the trade gap of the TAR and other poor western provinces with the rest of China in 1983 was almost equivalent to the total subsidies received by these provinces. In particular, they pointed out that 94 percent of merchandise sold in the TAR in 1983 
was imported from the rest of China. ${ }^{(17)}$ They also noted that financial outflows from these provinces in some cases were equivalent to the entire sum of central government subsidies flowing into the same provinces. ${ }^{(18)}$

While the data is not publicly available to update these earlier estimations, it is fairly obvious that these observations hold as much, if not more, in the present as in the past. The relative de-industrialisation of the local economy, together with the increasing conspicuous consumption of imports in the urban areas, implies that local production contributes relatively less to local consumption than it did in the past. Similarly, the increasing technological content of large-scale construction projects implies that these projects are also probably increasingly based on imported rather than locallysourced inputs, as indicated by the above data on external trade. Thus, it is quite likely that, in relative structural terms, the trade deficit of the TAR with other Chinese provinces has worsened since the early 1980s.

In other words, the high import content of local consumption and investment describes the structure of boomerang aid, in that most subsidies entering the TAR leave almost immediately via the trade account. Subsidies therefore add little to local economic value-added except by way of profits earned by intermediaries or wages earned through employment generated by the subsidies. However, when these profits and wages are earned by non-locals, they eventually result in financial outflows as profits and wages are "repatriated" to other parts of China, as discussed below. Hence, the only way to sustain growth in this context is to intensify the flow of subsidies in order to generate more turn-over, although this would also tend to accentuate the delinking of such flows from locally-oriented forms of accumulation.

\section{Instituted dependence and effective discrimination}

Returning to arguments of Wang and Bai, despite their pertinent insights, their analysis is problematic given that it is rooted in a culturally-derogative interpretation of why these perversions of development were taking place. They attributed the causes to the "intrinsic backwardness" of ethnic minorities in these remote western provinces, arguing that such backwardness resulted in a lack of investment demand rather than a shortage of savings. As a result, subsidies remained under- or poorly utilised, local capital accumulation did not take off as it had among the Han, and nothing inhibited funds from flowing out of the region or being spent on imported consumption goods rather than synergising a nascent capitalist ethos. ${ }^{(19)}$ This variant of Marxist modernisation theory is a common narrative among Chinese scholars or officials even today. ${ }^{(20)}$

Wang and Bai unfortunately used their valuable insights to reinforce a Han paternalistic bias towards minority areas. Instead of identifying the state management of the economy under a context of ethnic subordination as a principle target of blame, they identified local modes of wealth creation and accumulation. This is especially ironic given that they ignored the fact that the TAR rural economy had only just decollectivised at the time of their field research, after being completely collectivised a little more than a decade earlier, or that there was little that was particularly traditional or intrinsic in the conditions they observed. The urban economy itself remained almost entirely state-controlled, more likely managed by Han rather than Tibetan cadres, particularly up to 1981. A corrective for their analysis is to turn the focus on the issue of ownership as a key to understanding the instituted foundations of dependence and how these generate polarisation, ethnic discrimination, and exclusion.

\section{Ownership and disempowerment}

Ownership here refers to the substantive question of who controls the main levers of the economy, whether through direct ownership of assets or through influence over policies guiding expenditures and investments, and how this determines the instituted patterns of structural change in the economy. Considering the previous discussion on subsidies in the TAR, it is clear how ownership in everything but the primary sector is more or less completely dominated by entities located outside the local economy. In particular, a large share of direct subsidies, possibly all of the large construction projects, and even many of the small ones are contracted to out-of-province companies, most of them stateowned. Even projects that would be ideally suited for using and improving local Tibetan expertise are also mostly contracted to out-of-province companies and mostly use Han migrant workers. When there is Tibetan participation, it is usually restricted to the lowest skill levels, and only rarely at the level of ownership or management. This fact is not only implied in the data; it can also be clearly observed on the

17. Wang and Bai, The Poverty of Plenty, op. cit., pp. 75-76.

18. Ibid., pp. 71-72.

19. Ibid.

20. I noted this regularly during my field work. For an excellent discussion, see Emily T. Yeh, "Tropes of indolence and the cultural politics of development in Lhasa, Tibet," Annals of the Association of American Geographers, vol. 97, n³, 2007, pp. 593-612. 
ground. It is certainly not disputed by local scholars and officials, some of whom argue that this policy is motivated by the need for technical assistance and capacity building, and others that it is simply about choosing the best for your money, while others admit that there is simply no other choice - the terms are dictated by the hands that feed. ${ }^{(21)}$ In terms of these hands that feed, the policy of offering subsidised contracts to out-of-province companies is in part a necessary means to leverage the self-interest of various wealthy provinces in their support of central government investment strategies. However, even centrally-subsidised local government expenditures unconnected to provincial aid projects are similarly spent on out-of-province units, reflecting the fact that the coordination of such investment strategies is largely determined by the larger regional and national development priorities of Beijing, within which the interests of disempowered Tibetan locals carry little weight. Aid effectively becomes a form of industrial support for engineering and construction companies. Contracts often represent very profitable windfalls, up for grab on a one-time basis and with little concern for long-term sustainability. The railroad is an excellent example, given that companies participating in this project acquire a technical and managerial expertise that prepares them to compete on an international scale. U.S. defence spending or international tied aid follows much the same logic.

While this strategy in the Tibetan areas might be useful for building strong and competitive national firms, the development of locally-owned businesses and local expertise tends to be sidelined in the process. Ownership in the local economy is progressively transferred to non-Tibetan outsiders, in the relative sense that economic value-added is less and less concentrated where Tibetans have ownership (i.e. the countryside), and increasingly based in the urban areas or in infrastructure and other economic projects where ownership is retained by the investor (such as the railway, a hydroelectric project, or a mine). It is usually only the smaller "welfare" projects that might be donated to local governments or communities, such as houses, schools, clinics, or memorial statues, although even some of these are often transferred at a cost to the recipient, such as in the case of housing relocations, where grants to rebuild houses often cover only a fraction of the building costs. ${ }^{(22)}$

These institutional characteristics of ownership are important determinants of inefficiencies in the TAR. Beyond the more dramatic cases of wasteful spending, ${ }^{(23)}$ externalised patterns of ownership are at the root of the problem of trade deficits and financial outflows, much more so than lack of in- vestment demand or attributes of "intrinsic backwardness" as argued by Wang and Bai (if indeed their hypothesis has any validity). The externalised patterns result in a low circulation of profits and wages in the local economy due to considerable leakage from the province. Out-of-province companies tend to retain and "repatriate" their profits from the lucrative construction contracts, investing them in other national projects rather than in the local economy. Companies and their staff and workers usually return home or move on to other national jobsites upon completion of the projects, taking away the benefits of the acquired skills and earnings rather than investing or spending them in the local economy. In other words, money goes in and goes out without much turnover to benefit local production or demand, besides a skimming of trade and services, which again is dominated by outsiders and based on imports from elsewhere in China. Within this context, even if mining proves to be a new "pillar," it will tend to reinforce the already entrenched dualism of the economy, given its high-tech and enclave character, together with the fact that processing will most likely take place outside the province. Finally, corruption further reinforces this process. Unlike elsewhere in China, when project funding is diverted through corruption, it is usually diverted outside the TAR.

Even tourism and related industries, which have come to be touted as the new pillars of growth for the TAR, function in a similar manner, insofar as much of these industries is controlled by out-of-province businesses and employment dominated by migrant labour. A large share of tourism revenue therefore simply leaves the region after a short circulation, perhaps not much longer than the tourists themselves, or else is saved for later repatriation. Investment in tourism is similarly limited by its enclave nature, aimed at accessing and profiting from tourist circuits while carrying few incentives for the diversified reinvestment of profits in the local economy once such access is sufficiently leveraged. Under such circumstances, the tourist industry will most likely accentuate the externalised flows of wealth rather than incentivising local accumulation. The Tibetan medicine industry,

21. Various versions of these arguments were repeated to me in numerous interviews and conversations with Han Chinese scholars and officials, including those held at a recent conference on Tibet convened in Beijing by the China Tibetology Research Centre in October 2008.

22. See Emily T. Yeh and Mark Henderson, "Interpreting Tibet's urbanization: Administrative scales and discourses of modernization," Journal of the International Association of Tibetan Studies, vol. 4. See also Robin in this issue.

23. See Fischer, State Growth and Social Exclusion, op. cit., pp. 74-82, for analysis of how the institutional characteristics of ownership result in pervasive inefficiencies and even abuses in the use of subsidies. 
which is increasingly attracting the attention of Han investors, follows similar patterns in which ownership and head offices are increasingly located outside of Tibetan areas.

In sum, the instituted channels through which subsidies are spent in the local economies of the Tibetan areas are at the root of boomerang aid. In the absence of protection or promotion of locally-oriented forms of ownership, subsidy intensification simply reinforces externalised patterns of ownership, which in turn provide the institutional foundation for the acceleration of externalised wealth flows, thereby shortcircuiting local processes of accumulation and reinforcing subsidy dependence. This is similar to the argument of Wang and Bai, although they confused symptoms with causes by postulating that inefficiencies were due to the intrinsic backwardness of the minorities themselves, rather than to their political disempowerment and subordination to Han-centred political and economic processes. Indeed, such forced dependent integration into the rest of China is probably exactly what the government had in mind with its subsidisation strategies in the Tibetan areas.

\section{From dependence to polarisation and discrimination}

The accentuation of externalised flows of wealth creates the conditions for ethnic polarisation and effectively discriminatory forms of exclusion. Locally-oriented processes of wealth circulation are short-circuited in deference to sources of wealth that are located outside the local economy, which in turn accentuates an already-pronounced sectoral polarisation, as analysed in section one. There is little to bridge the increasing dualism of the local economy between the two extremes of the local rural economy and the heavily-subsidised modern urban economy. As a result, most local Tibetans face increasing hurdles to integration into the rapidly growing parts of the economy, particularly in light of their much lower education levels, especially at the secondary level where fluency in Chinese is mostly acquired. These challenges are further exacerbated by the presence of Han and Muslim Chinese migrants who are attracted to the artificially-subsidised affluence of the cities and towns of the TAR. The migrants are hardly to blame, as they are merely following the same economic incentives that attract many $\mathrm{Ti}$ betans from the countryside to these same cities and towns, including many Tibetans from Tibetan areas outside the TAR. Rather, the causes of the polarising dynamics reside in the way the subsidies are channelled into the economy. Because flows of wealth become increasingly centred out- side the local economy, the main beneficiaries of growth are those who are well-positioned to access these externalised flows, be they Tibetan or Chinese, government officials, traders and businesspeople, or even formal sector workers. Moreover, because these flows are instituted by members of the dominant Han Chinese nationality, they produce structures of advantage along axes that include important Han Chinese attributes, such as Chinese fluency, Chinese work cultures, and connections to government or business networks in China Proper. The social, political, and economic reproduction of this minority in the provincial labour force therefore bears little relation to the indigeneity of the $\mathrm{Ti}_{-}$ betan areas. There are few incentives to direct such elite wealth into locally-oriented forms of accumulation, given that much more money can be made with much greater ease through privileged access to state patronage, rather than through painstaking and relatively petty profit-making activities based in local productive activities. As a result, there is little dispersion or linkages of the externalised flows of wealth into the local economy, and outflows of wealth are privileged at the expense of local reinvestment. Those excluded from privileged access, whether the majority of $\mathrm{Ti}_{\mathrm{i}}$ betans or even many poor Chinese migrants, are in turn progressively marginalised from these dominant processes of accumulation driving growth in the local economy. A sharp polarisation of wealth thereby ensues.

The simplest way to represent the polarisation of wealth is through rising urban-rural inequality. The ratio of per capita urban disposable household income over per capita rural household income in the TAR, already the highest in China in 1995, increased sharply to a peak of 5.8 in 2002 (see Figure 7), a level never before seen in the PRC, where urbanrural inequality is generally a serious concern. ${ }^{(24)}$ Moreover, this sharp increase occurred precisely at the same time as it was falling nationally and in every other western province due to a combination of pro-rural poverty reduction strategies and the agricultural recovery from 1994 to 1997. The disparity increase in the TAR reflects the fact that real rural incomes were stagnant throughout the 1990s according to official data, while urban incomes in the TAR were above the national average due to a surge in the wages of staff and workers (mostly state-sector), which reached the highest in China in 2002 and 2004. In other words, the take-off of the TAR

24. For the TAR, urban per capita total income data is used from 2002 onwards rather than usual data on urban per capita disposable income, given large discrepancies that appear in these data from 2002 onwards. See Fischer, "A Theory of Polarisation, Exclusion and Conflict," op. cit., p. 166, for further details on the analysis of the data provided here. 
Figure 7. Urban-rural inequality, selected provinces, constant 2004 RMB

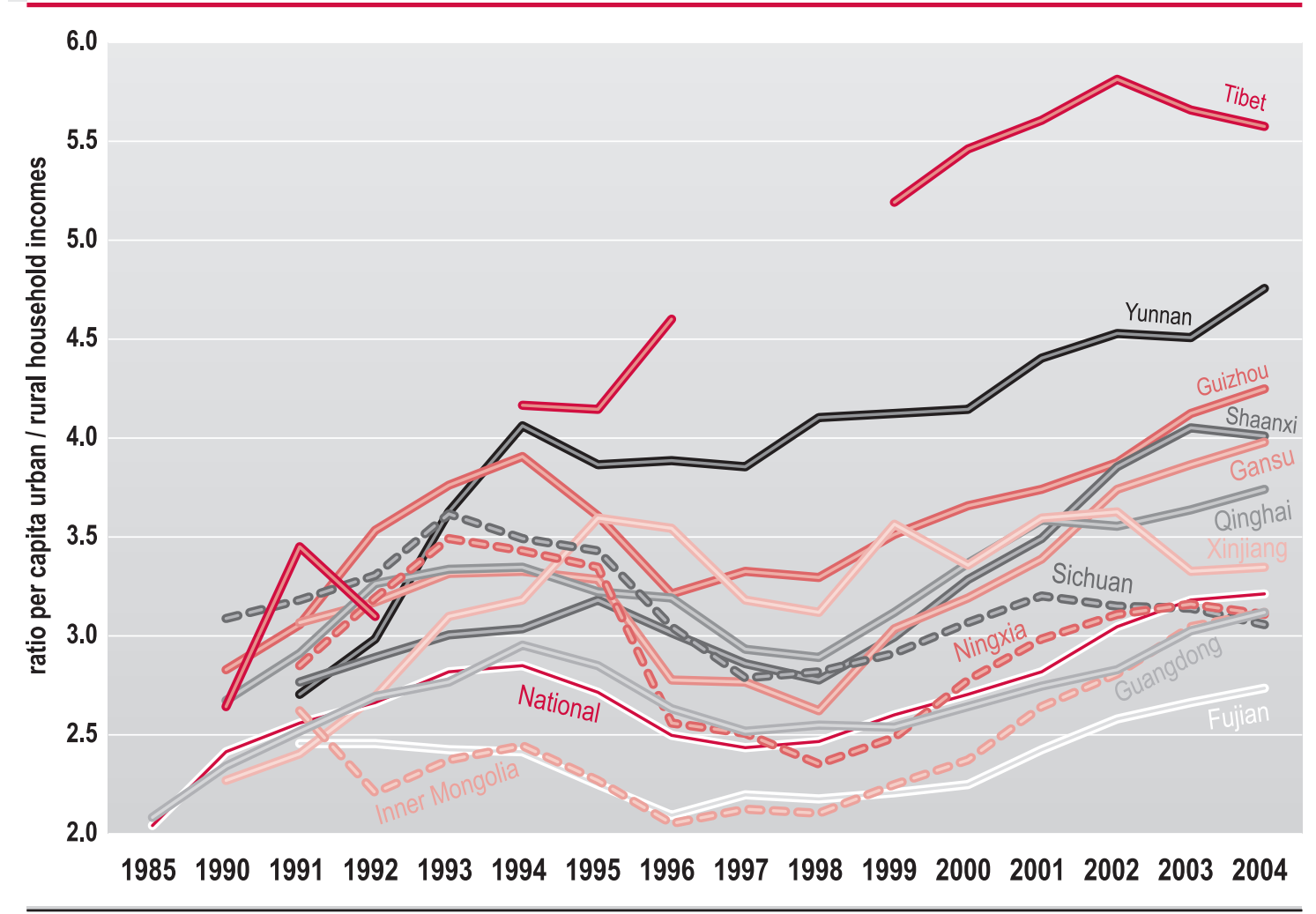

Sources: China Statistical Yearbook (2005, Tables 9-5, 10-15 and 10-21) and equivalent tables in previous yearbooks.

in the mid-1990s was primarily urban and excessively delinked from the local rural economy, at least up until the early 2000s.

Urban-rural inequality started to fall in the TAR after 2002, partly reflecting strong growth in official rural incomes after 2002. However, if these data do in fact represent real changes, the reversal in urban-rural inequality in the TAR from 2002 onwards might also be explained by the fact that the Tibetan labour force experienced one of the fastest, albeit latest shifts out of agriculture from the late 1990s onwards. The TAR had the most agrarian workforce in China up to 1999 , with 76 percent of the labour force employed in the primary sector. This primary share then suddenly fell by more than 12 percent up to 2004, even while the TAR remained one of the most agrarian provinces in China. ${ }^{(25)}$ This corroborates strongly with the recent field observations by Goldstein et al (2008), ${ }^{(26)}$ who argue that a rapid "paradigm shift" has taken place in rural Tibet from a predominantly subsistence agricultural economy to a new mixed economy in which non-farm income plays a dominant role. Given that rural off-farm economic opportunities in Tibetan areas re- main limited compared to most other regions of China, shifts out of agriculture in these areas largely imply urbanisation. Rapid urbanisation in turn tends to balance out urban-rural inequality, if only by reducing the absolute number people in the rural areas.

Parallel to these transitions, urban-rural inequality has also probably transitioned into intra-urban inequality since the late 1990s. It is difficult to derive an exact measurement of urban inequality in the TAR, given that the urban workforce is dominated by non-Tibetan migrant workers, who are not usually included in any of the household surveys (which only include permanent residents). Intra-urban inequality among those registered as permanently-residing was already high in the late 1990s in comparison to the rest of China, which can be explained by the fact that about half of the urban workforce was employed as relatively privileged state-sector staff and workers and benefited from some of the highest salaries

25. See Fischer, "Educating for Exclusion in Western China," art. cit., for further details.

26. Goldstein, Melvyn C., Geoff Childs, and Puchung Wangdui, '“Going for Income' in Village Tibet: A Longitudinal Analysis of Change and Adaptation, 1997-2007," Asian Survey, vol. $48, n^{\circ} 3,2008$, pp. 514-534. 
in the country, while the unprivileged lower half experienced some of the highest urban poverty rates in China. ${ }^{(27)}$

From this baseline in the late 1990s, there are strong indications that intra-urban inequality increased much more sharply in the TAR than elsewhere in China. ${ }^{(28)}$ This suggests that little urban wealth in the TAR dispersed outside the state sector, and that the wealth of those without access to state sector employment had rapidly fallen behind the sharp wage increases of those with state-sector employment. Essentially, there is a dual economy within the urban areas themselves, confirming the suggestion that the recent decline in urbanrural inequality is not so much an end of polarisation, but rather a reconstitution of such polarisation in the urban areas through urbanisation, with intra-urban inequality becoming a new fault line of polarisation in the region.

It is also important to note that the educational divide does not necessarily follow the urban-rural divide. About 41 percent of the permanent resident adult city population in the TAR was illiterate in 2004, according to official surveys. This is an exceptionally high level of urban illiteracy for China, with no parallel in any other province. For various reasons, most of these illiterates were probably Tibetan.

In this context, the Tibetans more suited to profit from the instituted patterns of growth comprise the 12 percent of Tibetans with some form of secondary education or above in 2005. ${ }^{(29)}$ These are probably the only Tibetans who have a decent degree of fluency in Chinese. Together with Tibetan migrants from eastern Tibet in Sichuan, they are therefore the only ones who can hope to take advantage of economic opportunities based on Chinese fluency, Chinese work cultures, and connections to government or business networks with China. However, even these relatively educated $\mathrm{Ti}$ betans tend to face strong exclusionary pressures in local employment, given that their education (particularly their $\mathrm{Chi}$ nese fluency) is generally poorer than that of migrants competing for jobs at similar strata of the labour hierarchy, especially since the introduction of competitive selection procedures for public employment. ${ }^{(30)}$

\section{Conclusion: From polarisation to exclusion}

This article examined how the instituting of rapid growth in the Tibetan areas of west China since the mid-1990s has itself been a crucial factor exacerbating the unresolved contestations of Chinese rule in these areas through its accentuation of polarisation and effective ethnic discrimination. This was first analysed in terms of the sectoral structure of rapid economic growth in the TAR since the early 1990s. Notably, sectoral transformation in the TAR economy occurred much more rapidly than in other western provinces in China. It was unique in that it was based mostly on alternating bouts of expansion in either government administration or largescale construction projects, both disconnected from local productive activities. Hence, there was a sharp divergence between the primary and tertiary shares of the GDP, with little secondary productivities activities to link the two, contrary to all other cases in China.

Second, polarisation was rooted in heavily-subsidised state-led development strategies of expenditure and investment, which together were equivalent to more than the total economic activity in the TAR since 2001. This situation is explained by the fact that the development strategies have intensified international and domestic trade deficits as well as financial outflows at the expense of local reinvestment or accumulation. While the recently completed railway from Qinghai to the TAR is one extreme example of such strategies, the character of these strategies was well entrenched since the late 1960s. The railway was merely an intensification of the institutional norms guiding the subsidisation of this politically-sensitive region since the later Maoist period. As a result, recent strategies have not significantly altered the long-term trend of very intense and very inefficient subsidisation. Rather, rapid growth since the mid-1990s has been the consequence of another bout of inefficient subsidy intensification.

The last section examined how patterns of ownership in the local economy provide the foundation for such inefficiencies and external dependence. Resultant polarisation and effective ethnic discrimination are reflected by rising urban-rural and intra-urban inequalities in the TAR to levels much higher than elsewhere in China. Given that most of the reins driving wealth creation and accumulation outside agriculture are located outside the TAR, development strategies intensify an externalisation of wealth flows within the upper layers of the economic structure, in the sense that inflows and outflows of financial and other resources are prioritised and facilitated over and above comparable flows within the local economy. Outflows of wealth are thereby exacerbated even while subsidies and investment pour in, offering little propensity for locally-oriented forms of circulation or accumulation.

Because wealth is closely associated with positions of access to these externally-oriented flows driving growth, the state-

27. See Fischer, State Growth and Social Exclusion, op. cit., pp. 121-123 for further detail.

28. See Fischer, "Educating for Exclusion", art. cit, p. 11-13 for further detail

29. Calculated from CSY, 2006, Table 4-12. 
subsidised development strategies carry an important ethnically-discriminatory institutional bias. This does not imply that all Tibetans are necessarily disadvantaged, but that the wealth of the well positioned, whether Chinese or Tibetan, is increasingly determined by factors located outside the local economy and instituted along lines that confer advantage not only to political obedience, but more generally to cultural or linguistic attributes deriving from members of the dominant group that controls the externalised flows. In the Tibetan context, these attributes include Chinese fluency, Chinese work cultures, and connections to government or business networks in China Proper. The Tibetans who are most likely to excel in these attributes are those with secondary education and above, who comprised about 12 percent of the population in 2005.

This is not to say that the average Tibetan has not benefited from growth; rising per capita GDP suggests that Tibetans on average have in fact been enjoying gradual improvement in their economic situations through the "trickle down" effect. Yet it would be surprising if these improvements had not taken place, given the sheer torrent of subsidies that the central government has channelled into the TAR. What is surprising is how little does in fact trickle down. The government argues that this is not a problem so long as the situation of the average Tibetan is gradually improving, although this defence ignores the exclusionary implications of polarisation, which lead to a form of economic segregation based on privileged access to the state-controlled levers of almost all aspects of the economy outside agriculture.

Importantly, we can observe these exclusionary processes operating even among relatively well-educated Tibetans. Some of the strongest exclusionary pressures are faced by Tibetans who in fact offer the greatest potential to overcome skills disjunctures or culturally-defined axes of discrimination, such as upwardly-mobile rural migrants, high school and university graduates, or laid-off state sector workers. This stratum of the labour force is under considerable competitive pressure due to the rapidly inflating institutional criteria that accompany the massive increases in subsidisation and investment from elsewhere in China. While inequality provides an important signal of these processes, it does not describe the entirety of exclusionary processes at work, given that many of those facing urban exclusion do not necessarily show up at the bottom end of the regional income distribution.

In this sense, our understanding of current tensions in Tibet needs to be grounded not only in the historical context of political subordination but also in the heightened degree of economic and social polarisation generated by the latest phase of intense subsidisation since the mid-1990s. Local initiatives and locally-generated investment and accumulation play a very minute role in the overall processes of economic change in the Tibetan areas. In the tense political environment, they might even be discouraged. In the TAR in particular, where subsidisation has reached its zenith, the local Tibetan population has been rendered more or less irrelevant as agents causing growth. Meaningful decentralisation has simply not taken place in Tibet the way it has in most other areas of China during the reform period.

This particular lack of agency exacerbates a feeling of alienation despite all of the monumental change and pockets of affluence. The policies that guide development in Tibet have been essentially promulgated from Beijing as top-down dictates following the trends of national development policy. Policies are then implemented, effectively or ineffectively, by local authorities, themselves appointed by Beijing, with the assistance of a corps of professionals and cadres from around the country on terms of duty that usually last two to three years. Elite Tibetans often make up a large share of locallevel government officials, although rarely at the most senior positions or with any substantive power. Due to the fiscal monopoly of Beijing and the political and security paranoia that grips the Tibetan areas, these local Tibetan officials mostly toe the line set out from above. And even these privileged Tibetans must face regular humiliation in the form of an evermore-confident sense of Han chauvinism from their Chinese superiors.

In this light, it is true that the CCP has spent a great deal of money in Tibet, but not necessarily on Tibetans. It is probably not the case that China has taken more from Tibet than it has given, as is often argued by many Tibetan exiles. However, whatever China has given to Tibet, it has largely given to itself, in the sense that the recipients are mostly Han Chinese. Like a boomerang, such aid returns to its sender while debilitating the agency of its purported beneficiary. Indeed, this may be precisely what Beijing intends by such strategies. However, in this case, it is also perfectly logical that the consequences would accentuate a perception among Tibetans that autonomy is urgently needed in order to effectively address their rapid marginalisation within development. •

30. See Fischer, "Educating for Exclusion in Western China," art. cit., for a detailed analysis of these exclusionary processes. 


\title{
Population Debates in Tibet
}

\author{
Adapted from Andrew M. Fischer: \\ - "Population Invasion' versus Urban Exclusion in the Tibetan Areas of Western China," Population and \\ Development Review, No. 34(4), December 2008, pp. 631-662.
}

As elsewhere in the world, population transitions have been fundamental to the appearance of modernity in Tibet. These transitions include population growth, urbanisation, and increased non-Tibetan in-migration from other parts of China (largely Han Chinese and, to a lesser extent, Chinese Muslims). However, the fact that these population transitions started around the same time as communist rule in 1950 has led to their conflation with the related but distinct issue of occupation. As a result, some of the most vigorous condemnations as well as defences of PRC rule in Tibet have come to be framed in terms of population.

Despite the reigning view in the West and among Tibetan exiles that Han Chinese migrants are flooding the Tibetan areas, possibly reducing Tibetans to a minority in their own land, this perception is partially misconceived. It is only in the main strategic cities and towns of Tibet where it can be plausibly argued that Han are outnumbering Tibetans. This is counterbalanced by more rapid rates of natural population increase in Tibetan rural areas - among the highest in China. Notably, Tibetan areas remain among the most rural of China, and Tibetan rural areas remain almost entirely Tibetan, even in eastern Tibet outside the TAR. According to the 2000 census in China, Tibetans were overwhelmingly rural in all of the five Chinese provinces that incorporate Tibetan areas, with 87.2 percent living in rural areas overall, ranging from 91.4 percent in Qinghai, to 90.9 percent in Gansu, 89.5 percent in Sichuan, 84.8 percent in the TAR and 80 percent in Yunnan. Rates of population increase among these rural Tibetans are significantly higher than among the Han (although these rates have been falling, as elsewhere in China). In contrast, in-migrating Han Chinese do not tend to bring their families and settle, with the exception of some Muslims. Thus, it is actually quite plausible that the proportion of Tibetans in the overall population has been rising, not falling, particu- larly in Tibetan areas outside of the TAR that are much less subsidised and thus attract relatively fewer migrants. However, even if Tibetans are a majority of the population, most of this majority resides in rural areas, where it is not visible to casual observation.

From this perspective, the perception of population swamping is essentially an urban-centric assessment of the changing ethnic composition of Tibet. Rising population density and rapid urban expansion can give the visual impression that the more urbanised or economically successful groups (Han or Muslims) are becoming more dominant, even while they are only maintaining or even losing their share in the overall population.

This is not to say that there is no problem, but that the problem is misinterpreted. The fundamental problem is that non-Tibetan migrants definitely dominate urban economic opportunities. Cities and towns are precisely where the political and economic levers of power are controlled and the long-term trajectories of ethnic stratification determined, particularly at this critical transitional juncture in Tibet.

Therefore, Tibetan perceptions of population swamping seem to express a malaise with exclusionary processes in the context of rapid urban-centred development. While probably misconceived, these perceptions can be seen as a reactive lens through which Tibetans interpret their very legitimate grievances within a context of stark political and economic disempowerment. 